\title{
College Students of Art Design Innovative Entrepreneurship Analysis
}

\author{
Zheng Shuo
}

\author{
Changsha Environmental Protection College
}

Key Words: Entrepreneurship; Art design; Talent Cultivation

\begin{abstract}
To promote the development of domestic economy as well as the independent profession choosing and entrepreneurship, Prime Minister Li Keqiang put forward the call of popular entrepreneurship and innovation during the World Economic Forum in 2014. To respond to the call of the State Council, a new situation of "popular entrepreneurship and everyone innovation" has formed. Art design is currently a rising hot industry, which has low requirement for the entrepreneurs, and provides a lot of preferential policies to the financing of small enterprises in China. To start up business, we need not only capital support, but also the professional unique design ability. To guarantee the entrepreneurship of the art design personnel, this thesis will start from improving the art design personnel's application ability, conducting analysis to the training mode of the art design talents in China.
\end{abstract}

\section{Introduction}

Ever since the reform and opening-up policy, the economy in China is developing rapidly, with the economic growth rate ranking the first around the world and becoming the second economic entity in the world. China's economic policy contributes a lot to these achievements. The key of realizing steady economic development is to guarantee the employment rate of the masses. However, with such great number of population, as well as the increasing requirements of enterprises to talents, the pressure of employment in China is rising. The presenting of "popular entrepreneurship and innovation" not only helps to remit domestic employment pressure, but also guarantees the smooth and steady development of China's economy. The establishment of "popular entrepreneurship and innovation" not only helps to remit domestic employment pressure, but also guarantees the stable development of economy in China. According to the data published by the Ministry of Education, the number of undergraduates from colleges in China in 2016 reaches to 7.65 million. Comparing to choosing an occupation, it would be better if they can conduct entrepreneurship with their advantages in their major, which helps to remit domestic employment pressure and at the same time helps the college undergraduates to realize their value of life.

\section{The Current Employment Status of Undergraduates in China}

With the background of market economy, the number of employment posts and that of occupation choosing population does not have much of a difference, with the posts being able to hold the population to some extent. However, it is not that easy to find an expected job. We should pay more attention to the development prospect of the industry and the post during occupation choosing because the treatment of job is not the only factor which matters. Nevertheless, a lot of undergraduates have neglected this and are too blind during occupation choosing. Without a clear plan for their career, they are lack of pertinence in the on-campus or social job fairs and are likely to follow suit when choosing career or position. A lot of the students are moving around with their 
resumes, having no clear goal. Inside their hearts, there are no concepts like "what do I need" or "what can I have". The blindness during occupation choosing is the most common phenomenon in undergraduate employment.

Another common phenomenon in undergraduate employment is the limited occupation choosing orientation. The width of thought decides one's development in future, and this also applies to employment. A lot of undergraduates have very limited occupation choosing orientation, with the following evidences: (1) They choose limited job site. As the saying goes, "Man struggles upwards and water flows downwards." Everyone has a struggling heart. Being the cresset of first-tier cities in China, Beijing, Shanghai and Guangzhou are the dreaming places for many people, not excluding the undergraduates. They are too inflexible during occupation choosing and have neglected the fact that though the treatment in big cities is great, the competition is quite fierce, too. (2) They have very limited career planning. Reasonable career planning is beneficial to individual development. However, the undergraduates are always geared to the needs of the job and focuses on the needed major only.

The development of the society relies heavily on human labor, and human beings are realizing their own value during work. Scholars, doctors and teachers are playing their corresponding role in the society through their labor. Currently, a lot of undergraduates are lack of sufficient cognition to the society as well as themselves, and they do not have an occupation choosing concept. Many students form bad habits during their college time and are still living in the world of internet after graduation, being lack of occupation choosing motivation. After graduation, some of them choose not to step out to the society and stay at home doing nothing. Plus, parents always spoil them without correct teaching, which is of common occurance, leading to the phenomenon of "boomerang kids."

\section{Favorable Factors for the Art Design Undergraduates to Conduct Entrepreneurship}

Compared to other majors, art design majors cover a wider range of content such as costume designing, interior design, architectural design, graphic design and landscape art design, etc. It can be said that art design is closely related to everyday life of human beings. With the continuous development of economy, people are having increasingly high standard to their quality of life. The relationship between art design are human beings' life is closer and closer under such background. Taking interior design as an example, it has entered the ordinary people's life. What's more, with the promotion of people's aesthetic value, the style of interior design is now diverse. Interior design is not only decorative, but it also helps to form a cozy atmosphere which improve the environmental comfort level. Facing with the increasing social needs, art design has now become a comparatively hot major. As long as you have a novel design philosophy and fine art quality, you will enjoy high probability of success when conducting entrepreneurship.

To promote the launching of "popular entrepreneurship and everyone innovation", the government has provided great support to the entrepreneurs. A lot of undergraduates enter the art design field by establishing studios. For a long period of time, China is very limited in the financing problem of private enterprises. Till 2015, to promote the development of micro and small enterprises, the Ministry of Finance of China published the < Notice About Small Profit-making Enterprise Income Tax Preferential Policies>. It is pointed out in the notice that the small and medium-sized enterprises which have an annual sales volume lower than 300,000 can enjoy the preferential policy of half tax. According to the data collected by the Bureau of Finance, China had a tax deduction and exemption of 102.535 Billion RMB in 2015 for the small and medium-sized enterprises. This has undoubtedly remitted the capital pressure for the entrepreneurs in art design 
field.

\section{Status Quo of Art Design Talents Cultivation in China}

First, the undergraduates of art design in technology institutes are of low overall quality and insufficient social practice ability, making them unable to adapt to the requirements of "popular entrepreneurship and everyone innovation." Second, the undergraduates are of weak artistic accomplishment and design thinking. Therefore, the things they design are lack of sense of time and space, formative feeling and abstraction. Third, undergraduates in technology institutes are lack of literary accomplishment. The current year's undergraduates in art design major are lack of overall quality and ability, with insufficient social practice ability, low innovation consciousness, weak entrepreneurship and poor independent living ability, and so on. All these together make the undergraduates in art design major unable to become the synthesizing type talents which the society needs and make it hard for them during employment or entrepreneurship.

To improve education, China has been devoted to the deepen reform of education and teaching in ways of enriching teaching methods and increasing investment in teaching attachments. Since the reform of education and teaching is now on its halfway, a lot of the technical institutes are now having limited teaching way. Teachers have been the core of courses and the students are lack of space and time for self-learning and self-thinking. The teaching method of "Repeating what the book says" is now still the main teaching method used in art design courses. The students with such teaching method can only read books, without their ability of creative thinking being effectively developed. The art design concept is from the students' thought. If the students are lack of creative thinking, they will not be competitive during work and are not likely to realize their dreams of self-employed. In the meantime, art design courses should not only include the theory part. The practice courses are absolutely necessary. A lot of technical institutes neglect the practice and focus on theory teaching, which has seriously hindered the development of students' practical ability.

With the development of the society, the core competence among enterprises has transited from capital and product competition to talents competition. Talents have become the importance guarantee of enterprise development. To promote the development, many enterprises have intensified the recruitment and raised the standards of recruitment. However, a lot of the technical institutes have not realized this. When formulating the objective of talents training, they failed to take the needs of enterprise and society in consideration, making the teaching content disjointed to the development of enterprises and society. This, as a consequence, leaves the students with scarce capacity during work. They cannot meet the enterprises' needs and are lack of competitiveness. This not only influences the students' employment, but also fails to meet the requirement of self-employed.

\section{Effective Measures to Improve Art Design Talents Cultivation Mode under Entrepreneurship Background}

Teachers are subject to conduct teaching, and the reinforcement of teachers is the key to guarantee the smoothness of color design course education work. The following measures can be taken. (1) Higher the employment standard of recruitment for teachers. The technical institutes should higher the employment standard of recruitment for teachers. They should be of professional theory knowledge as well as solid practical ability since the main concept of design is from practice. Also, the teachers should be of excellent language ability. (2) The current teachers should be trained. The technical institutes should reinforce the training of teachers. Besides the improvement of the 
teachers' level of expertise, the teaching methods of the teachers should be improved, too to generalize more perfect and rich teaching methods.

We should pay attention to "one introducing and three reinforcing" during curriculum system design. "One introducing" refers to the introducing of practical cases. The previously done social practice design project and tasks can be included in teaching to conduct simulation of actual combat training. Credit should be set independently for this so that the students should participate in market researching and the analyzing, tidying and formulating of strategies and design scheme. The faculty adviser can also play the role of enterprise consignor to guide the students to complete the simulation task. "Three reinforcing" refers to (1) reinforcing of entrepreneurial elective course. The entrepreneurship courses should be reinforced in elective courses, with systematical introduction to entrepreneurship theory, knowledge, skill and cases, etc; (2) reinforcing of cross-major \& interdisciplinary courses. The advantages of the comprehensive universities should be taken to reinforce the horizontal ties between art design major and management, economics and sociology, and so on, to widen the major covering, lighten the major and enhance the adaptation of major; and (3) reinforcing of entrepreneurship concept in specialized courses. The main task of specialized courses should certainly be the passing on of specialized knowledge. However, for the teachers who are responsible for cultivating the students' entrepreneurship consciousness and skills, they should choose the contents which are related to, beneficial and useful for the students' entrepreneurship cultivation during the teaching process. They should on purposely lead the students to entrepreneurship concept, thus to form the inter-infiltration and functional complementation among cultural courses, specialized courses and entrepreneurship courses.

Innovation concept is the soul of art design and also the motivation of art design development. In regards to design color courses, the technical institutes should lay emphasis on the cultivating of the students' innovation concept. The details are: (1) establishing the teaching concept of students being the core. Under the influence of exam-oriented education, the teaching method in China is inflexible and single, which hinders the development of the students' innovation concept. To improve the students' innovation concept ability, the teachers should establish the teaching concept of students being the core, giving the classes back to the students to guarantee their self-learning and self-developing; (2) holding design competition. The technical institutes can hold design competitions with the topic of art design and guarantee each student with the right of participation. Through competition, not only the students' independent innovation and design ability can be improved, the campus life can be enriched, with the improving of the cultural and art atmosphere in the schools.

Ideology is the precursor of action. The entrepreneurship education should firstly solve the problem of the students' acknowledgement of entrepreneurship. First, the entrepreneurship confidence should be strengthened. Entrepreneurs or managers as well as the people on the firing line who are of excellent performance can be invited to have an informal discussion to encourage and help the art designers who are qualified of self-employed through their success in entrepreneurship. Second, the students should be aware of their own advantages. They should know that the development of the society has brought great opportunities to the art design fields and the giant potential in this field needs more people to devote in the entrepreneurship. They should realize the advantage and opportunity they have. They should be encouraged to combine their major and the market as well as the need of the society to enhance the cultivation of their entrepreneurship ability. In short, a full-bodied entrepreneurship atmosphere should be created among the students to make them realize the necessity and urgency of entrepreneurship, thus to change their occupation choosing concept, building their entrepreneurship consciousness and spirit. 


\section{Conclusion}

Entrepreneurship is full of opportunities and challenges. With the increasing of pressure in market competition, the entrepreneurs are facing with great difficulty. Essentially, entrepreneurship is a double-edged sword. Some can realize their value of life while adding their value while some can be of heavy debt and utterly discredited. The main reason for this is that the failed ones are lack of analysis to the market. Through analyzing, the entrepreneurs can know about the competition pressure of the whole filed and prospect the potential. Therefore, each entrepreneur should deeply analyze the market before the entrepreneurship to guarantee the correct conducting of entrepreneurship, thus to realize their life value.

\section{Acknowledgment}

The title of this paper is the research on the innovation and Entrepreneurship of college students participating in the new rural planning and design, Serial number: 16B110.

\section{Bibliography:}

[1] Studio: an Effective Platform for Students' Innovation Entreprenuership Education [J] Fan Xin, Yang Yanqun, School party construction and ideological education, 2012 (36);

[2] Carry Out Studio Teaching Mode and Cultivate Design Talents of "Two Haves and Three Practices" [J] Ye Jinsong, Art Panorama, 2010 (12)

[3] A Rustic Opinion on the Graduation Project Educational Reform of Art Design Majors in Technical Institutes under Entrepreneurship Concept [J] Ji Xiaohui, Journal of Lanzhou Institute of Education, 2015 (03) 